REVISTA DE GESTÃO E SECRETARIADO

MANAGEMENT AND ADMINISTRATIVE

PROFESSIONAL REVIEW

ISSN: 2178-9010
Revista GeSec

São Paulo, SP, Brasil

v. 12 , n. 2 , p. $225-252$

maio /ago. 2021

DOI: http://dx.doi.org/10.7769/gesec.v12i2.1191

\title{
Reflexo do planejamento tributário no endividamento das empresas não financeiras listadas na Brasil Bolsa Balcão (B3)
}

\section{Reflection of Tax Planning in the Debt of Non-Financial Companies Listed in Brasil Bolsa Balcão (B3)}

\author{
Ayanna Karoline da Fonseca ${ }^{1}$ \\ Deylane Mendes Sirqueira ${ }^{2}$ \\ Risolene Alves de Macena Araújo ${ }^{3}$ \\ Inajá Allane Santos Garcia ${ }^{4}$
}

\section{Resumo}

O objetivo deste estudo é investigar qual o reflexo do planejamento tributário no endividamento das empresas não financeiras listadas na B3. Para isso, utilizou-se o método da Regressão Quantílica e uma amostra com dados em painel, composta sob duas concepções do planejamento tributário: taxa de imposto efetiva (ETR) e ETR desembolsada (ETRCash). Sob a perspectiva da ETR, observou-se que, no menor quantil, empresas mais agressivas fiscalmente são menos endividadas do que aquelas que adotam planejamento tributário moderado. Enquanto, considerando a ETRCash, observou-se que práticas de planejamento fiscal agressiva estão associadas ao endividamento das empresas dos quantis menores. Acredita-se que tais empresas, mesmo não sendo favorecidas com altos créditos de terceiros, se utilizam do endividamento como estratégia para pagar menos tributos.

Palavras-chaves: Brasil Bolsa Balcão (B3). Endividamento. Planejamento Tributário. ETR. ETRCash.

\footnotetext{
${ }^{1}$ Graduada em Ciências Contábeis pela Universidade Federal do Pará (UFPA).

${ }^{2}$ Graduada em Ciências Contábeis pela UFPA.

3 Doutoranda no Programa de Pós-graduação em Ciências Contábeis da Universidade Federal da Paraíba (PPGCC/UFPB), Docente da UFPA.

${ }^{4}$ Doutoranda no Programa de Pós-graduação em Ciências Contábeis da Universidade Federal da Paraíba (PPGCC/UFPB), Docente da UFPA.
} 


\begin{abstract}
The objective of this research is to investigate the aftermaths of tax plan on B3 non-bank companies' debt. To achieve it, quantile regression was employed in a panel data sample, based on two tax plan conceptions: Effective Tax Rate (ETR) and Cash ETR (ETRCash). Under ETR perspective, it has been revealed that, in the lesser quantile, tax aggressive companies hold less debit than those with moderate tax plan. As for ETRCash, it has been revealed that aggressive tax planning practices are associated with debit in companies belonging to the greater quantile. It is believed that such companies use debt as a strategy to pay less taxes, even if they are not being favored with higher third-party debts.
\end{abstract}

Keywords: Brasil Bolsa Balcão (B3). Debt. Tax Planning. ETR. ETRCash.

\title{
Introdução
}

Em 2015 o Instituto de Pesquisa Econômica Aplicada (IPEA), evidenciou que o percentual desembolsado pelas empresas destinado ao pagamento de tributos alcançou o equivalente a 33,4\% do Produto Interno Bruto (PIB) (IPEA, 2015), representando o maior da América Latina e um dos maiores do mundo. Segundo Kume (2019), dentre os países-membros da Organização Mundial do Comécio (OMC), o Brasil ocupa atualmente o $14^{\circ}$ lugar das maiores tarifas de imposto, sejam elas, nominais ou efetivamente pagas, o que implica dizer que as empresas brasileiras precisam arcar com altas cargas tributárias para manutenção de suas operações.

Essa realidade atinge significativamente a competitividade dessas empresas, influenciando na formação do preço de seus produtos e serviços, o que está intrinsecamente ligado à sua sobrevivência, pois, a alta carga tributária brasileira consome parte significativa do resultado financeiro das companhias (Ávila, Malaquias \& Silva, 2013; IBPT, 2019). Nesse contexto, é importante destacar que as companhias listadas na bolsa de valores Brasil Bolsa Balcão (B3) estão entre as maiores devedoras de tributos do Brasil (IBPT, 2019), logo, observase que o peso dos impostos sobre a estrutura de custos das empresas brasileiras é muito elevado, conduzindo, algumas vezes, as multinacionais a realizarem investimentos em paraísos fiscais, com o objetivo de escaparem das altas cargas tributárias do país de origem (Martinez, Ribeiro \& Funchal, 2019). Ou seja, as entidades tendem a recorrer as estratégias de gestão voltadas à minimização dos impactos negativos causados pelo pagamento de tributos. 
Araújo e Leite (2019) explicam que o planejamento tributário é de fundamental importância para a saúde financeira da entidade, pois, envolve um conjunto de práticas que visam atenuar o pagamento de tributos (impostos, taxas e contribuições) e aumentar, cada vez mais os lucros a serem distribuídos aos seus acionistas (Hanlon \& Heitzman, 2010; Santana, 2014). Ademais, percebe-se que onde há altas cargas de tributos e legislações tributárias embaraçosas, há um ambiente favorável às práticas de planejamento tributário (Dalmácio \& Rathke, 2019), dentre elas, a contração de empréstimos, a qual está incorre em altas taxas de juros, sendo esse um dos fatores responsáveis pelo nível de endividamento das entidades, uma vez que quanto mais empréstimos realizados, maiores são os juros passivos, utilizados para a dedução do lucro tributável.

Todavia, é imprescindível que a escolha por determinado planejamento tributário ocorra em função do trade-off entre os benefícios e os custos marginais de gerenciar os tributos (Chen, Chen, Cheng \& Shevlin, 2010). Nesse sentido, o presente estudo se propõe a investigar o reflexo do planejamento tributário no endividamento das empresas não financeiras listadas na Brasil Bolsa Balcão (B3), no período de 2011 a 2018. Para tanto, esta pesquisa fundamenta-se sobre a seguinte problemática: Qual reflexo do planejamento tributário no endividamento das empresas não financeiras listadas na Brasil Bolsa Balcão (B3), no período de 2011 a 2018 ?

Sendo assim, a presente pesquisa justifica-se por sugerir às entidades uma ferramenta para gestão empresarial, o planejamento tributário, o qual pode ser utilizado com o objetivo de reduzir as despesas com pagamentos de tributos, sobretudo no contexto brasileiro, que apresenta altas cargas tributárias sobre o lucro. Nesse sentido, entende-se que um planejamento tributário eficaz, além de trazer maior segurança para seus acionistas, torna-se um excelente instrumento de competitividade empresarial, uma vez que, quanto menos a entidade dispender recursos com os tributos, maior será alavancagem do seu negócio (Paula, 2018).

Além disso, Carpes e Frederico (2018) argumentam que as pesquisas sobre Planejamento Tributário ainda estão em estágio inicial, evoluindo lentamente ao longo dos anos, o que possibilita uma abertura para ampliação das pesquisas nessa área. Ressalta-se, ainda, que não foram encontradas pesquisas brasileiras publicadas recentes que tenham investigado, especificamente, o reflexo do planejamento tributário no nível endividamento das empresas de capital aberto; apenas verificou-se pesquisas sobre: i) a relação entre a tributação efetiva sobre o lucro, tamanho, endividamento, intensidade de capital, intensidade de estoques e lucratividade (Bispo, Calijuri \& Lima, 2009; Santos, Cavalcante \& Rodrigues, 2013); ii) relação entre a tributação do lucro e a estrutura de capital das grandes empresas (Pohlmann \& 
Iudícibus, 2010); e, iii) os reflexos doplanejamento fiscal na rentabilidade das empresas de capital aberto (Araújo \& Leite, 2018).

No tocante à metodologia aplicada vale destacar que, o planejamento tributário foi categorizado em "planejamento fiscal moderado" e "planejamento fiscal agressivo", em função da confrontação das variáveis Effective Tax Rate (ETR) e Cash Effective Tax Rate (CashETR) com a média da ETR das empresas do respectivo setor. Nesse sentido, espera-se que as informações levantadas nesta pesquisa fomentem o desenvolvimento de novas pesquisas sobre a temática, considerando que, no Brasil, é reduzido o número de pesquisas na área tributária, principalmente, quando se trata de planejamento tributário e seus reflexos no endividamento das empresas de capital aberto.

\section{Referencial Teórico}

\subsection{Planejamento Tributário}

Com base na literatura, observou-se que as pesquisas sobre planejamento tributário vêm se intensificando (Carpes \& Frederico, 2018), tendo como um dos focos de estudo a sugestão de ações que esperam uma economia dos custos tributários para as organizações. Nesse sentido, é provavel que a diminuição de cargas fiscais de uma entidade não apresente consequências negativas a longo prazo, e este é um dos fatores que determina que haja realização do planejamento tributário (Martinez \& Salles, 2018). Visto que, o planejamento tributário é um conjunto de condutas que o contribuinte pode realizar visando à busca por uma carga tributária menor, legalmente possível (Greco, 2008).

O planejamento tributário visa uma maior rentabilidade, garantindo assim, a continuidade e a competitividade empresarial (Araújo \& Leite, 2018), ao passo que a economia tributária tem como consequência uma maior capitalização da empresa, pois, reduz a quantidade de recursos repassados para o governo (Lima \& Duarte, 2007). Dessa forma, em um sistema tributário como o brasileiro, em que há constantes mudanças na legislação, com o objetivo de aumentar a arrecadação de impostos, é preciso que a empresa, além de estar preocupada com a redução do montante de tributos a ser pago, se esforce no sentido de maximizar o desempenho econômico-financeiro e, consequentemente, ofertar maior retorno para seus investidores (Santana, 2014), se utilizando de outras estratégias, que não sejam apenas as tributárias.

Sob essa perspectiva, o planejamento tributário funciona como um estudo preventivo, cujo objetivo é identificar os efeitos econômicos e jurídicos chegando a uma alternativa legal, 
menos onerosa à empresa (Fabretti, 2012; Martins, 2014). Logo, decisões contábeis são afetadas pela posição tributária da empresa, sobretudo nas entidades de capital fechado, onde se observa uma postura mais conservadora da gestão (Cloyd, Pratt \& Stock, 1996; Mills, 1998; Hanlon, 2005), uma vez que, o aumento do valor da entidade não está vinculado apenas à capacidade de pagar menos tributo, mas também de mitigar os riscos inerentes ao processo de tomada de decisões gerenciais. Sobre isso, Hanlon e Heitzman (2010) e Cerize (2017) argumentam que, os acionistas esperam ser representados pelos gestores no que concerne a maximização de lucros, fato que inclui a redução de passivos fiscais.

Embora existam algumas evidências isoladas na literatura, ainda não é conhecida toda a eficácia dos procedimentos de planejamento tributário adotados pelas empresas (Rezende, Dalmácio \& Rathke, 2019). O que se tem, são algumas das principais práticas utilizadas na redução da alíquota efetiva de IRPJ e CSLL, tais como: depreciação acelerada, juros sobre capital próprio, reorganização societária e incentivos fiscais (Rezende \& Nakao, 2012).

No mais, Vello e Martinez (2014), afirmam que quanto melhor o planejamento tributário das empresas, menos impostos são pagos e mais competitivas as firmas se tornam diante de seus concorrentes. A eficácia desse planejamento tributário pode ser mensurada de várias maneiras, dentre os indicadores levantados na literatura destacam-se a ETR e a ETRCash, os quais serão abordados no tópico seguinte.

\subsection{Mensuração do Planejamento Tributário}

A mensuração do planejanemento fiscal adotado pelas empresas pode ser calculada de diversos modos - GAAP ETR, ETR Current, ETR Cash, ETR Long Cash, ETR Differential. A escolha do método depende do objetivo de cada estudo, como, por exemplo, para medir o impacto dos impostos sobre os incentivos aos investimentos, verificar a carga tributária das empresas e auxiliar os gestores no estabelecimento de estratégias de gestão tributária (Araújo \& Leite, 2018). Neste estudo, foram utilizadas a ETR e a ETR Cash, as quais são definidas respectivamente como, a alíquota efetiva sobre o lucro da entidade e a alíquota efetiva dos tributos pagos (Desai \& Dharmapala, 2006; Dyreng, Hanlon \& Maydew, 2008; Armstrong, Blouin \& Larcker, 2011; Rashid, Anderson \& Warsame, 2019; Chiachio \& Martinez, 2019).

Corroborando, Ferreira e Souza (2018) destacam que as pesquisas em planejamento tributário têm sido voltadas, em grande parte, à análise de dados de empresas multinacionais, utilizando uma abordagem metodológica quantitativa e como um dos principais parâmetros de mensuração a Effective Tax Rate (ETR). Sobre isto, Shackelford e Shevlin (2001) acreditam 
que se o índice de ETR for menor que a alíquota nominal dos tributos incidentes sobre o lucro, há uma eficácia no planejamento tributário, pois, a variável ETR é capaz de medir o nível de agressividade tributária das empresas, demonstrando qual sua intensidade, podendo assim refletir nas decisões tomadas pelos usuários internos, ao passo que funciona como um instrumento gerencial relevante para administradores, economistas, contadores e políticos, que precisam ter acesso a informações tributárias (Giannini \& Maggiulli, 2002; Lammersen, 2002; Dunbar, Higgins, Phillips \& Plesko, 2010; Paste, 2017).

Todavia, Paste (2017) ressalta que, assim como outros indicadores, a ETR tem as suas limitações. Dentre essas limitações, Tang (2005) salienta a questão dos incentivos fiscais, que afetam substancialmente o imposto pago pelas empresas, e, por conseguinte, causam variações na ETR. Esses mesmos incentivos fazem parte da política de planejamento tributário (Gomes, 2011). Outra limitação ocorre pelo fato desse índice não retratar as estratégias de diferimento de tributos, além de ser afetado pelas compensações de prejuízos de anos anteriores (Wilkie, 1992; Hanlon \& Heitzman, 2010; Paste, 2017).

No que concerne a ETRCash, Chen et al. (2010) e Araújo e Leite (2019), ressaltam que, esta proxy indica o que efetivamente foi pago de tributos, eliminando a possibilidade de superavaliação das despesas com impostos correntes, os quais são oriundos de pagamentos extraordinários e compensações que já foram realizadas, bem como mitigar as diferenças causadas pelos impostos diferidos, que também afetam a alíquota efetiva de imposto. Além disso, a medição das ETRs passa a ser calculada a longo prazo, estimado em 10 anos ou, ainda, pode contemplar um período de 3 a 10 anos, conforme explicado por Hanlon e Heitzman (2010), assim, os encargos tributários são acompanhados a longo prazo, de forma cumulativa, não sofrendo tantas alterações decorrentes de compensações e abatimentos sobre o imposto (Hanlon \& Heitzman, 2010; Araújo, 2017).

Na presente pesquisa, a CashETR é estimada para identificar o nível de planejamento fiscal adotado pelas empresas que compõem a amostra. Para tanto, foi utilizado o modelo proposto por Hanlon e Heitzman (2010), considerando uma análise ao longo de 8 anos. Destaca-se, ainda, que a mensuração dos tributos pagos pelas empresas, considera-se somente as despesas correntes com tributos, que representam obrigações tributárias, ora registradas nas empresas e liquidadas junto às autoridades fiscais, no caso do Brasil, até o último dia do mês de março do ano subsequente. 


\subsection{Planejamento Tributário e Endividamento das Empresas}

Os indicadores de desempenho exercem um papel importante na análise econômicofinanceira das empresas. Nesse sentido, os índices de endividamento se destacam por demonstrar a capacidade das empresas em consumir os seus recursos próprios ou de terceiros, bem como, evidenciar a evolução do endividamento a longo prazo, representando, assim, um papel fundamental na ampliação das operações das companhias. A respeito disso, Correia e Ganzarolli (2019) evidenciam que esse indicador contribui para a tomada de decisão, ao passo que permite a análise do grau de comprometimento da empresa frente ao pagamento de seus credores.

Em contrapartida, o Planejamento Tributário é o estágio inicial de uma análise sistemática de alternativas diversas de tratamento tributário, com o objetivo de alcançar um imposto mínimo a ser pago (Megarani, Warno \& Fauzi, 2019). Geralmente é visto como um benefício para a entidade e seus acionistas, desde que o planejamento dos custos tributários implique em maiores fluxos de caixa e lucro líquido para a empresa e residualmente para seus acionistas (Blouin, 2014). Devido ao alto percentual incidente de tributo sobre o lucro, tornase interessante para as empresas, endividar-se, uma vez que uma forma de se obter benefícios fiscais ocorre por meio das despesas financeiras (Silva \& Valle, 2008; Pohlmann \& Iudícibus, 2010; Santos et al., 2013), assim como previsto na trade-off theory, ao afirmar que a empresa estabelece uma meta de endividamento para usufruir do benefício fiscal da dívida e consequentemente pagar tributos menores sem incorrer em riscos de falência (Myers, 1984). Todavia, este autor levantou uma proposta inicial, a Pecking Order Theory, defendendo que a estrutura de capital das empresas decorreria de um processo de funding hierarquizado, no qual as empresas obedeceriam a uma hierarquia com relação à utilização ou captação de recursos: os fundos gerados internamente estariam no topo das preferências, seguidos da emissão de dívidas e finalmente da emissão de ações como último recurso.

Dados divulgados pelo IBPT (2018), apontam que em 2017, cerca de $21,40 \%$ das empresas listadas na Bolsa de Valores de São Paulo (B3) possuíam dívidas tributárias com a União, e destacou ainda que esse percentual é elevado, motivando empresas a aderirem ao Programa Especial de Regularização Tributária (PERT). Tal situação remete-se ao posicionamento de Edward, Schwab e Shevlin (2015), os quais enxergam o planejamento tributário como uma fonte de financiamento para as empresas que enfrentam situações de restrições financeiras, já que elas terão uma maior necessidade de recursos financeiros. De acordo com estes autores, o recurso pode ser "adquirido" da autoridade fiscal, reduzindo o lucro 
tributável atual ou aumentando os créditos fiscais, por meio do planejamento tributário e, assim, reduzindo os tributos pagos no período corrente.

Brito e Lima (2005) afirmam que as empresas mais lucrativas são as que apresentam um maior nível de endividamento, ao passo que, quanto maior o lucro, maior o desembolso para o pagamento de tributos. Além disso, o nível de tributação se caracteriza como um dos principais fatores de endividamento das empresas, visto que as altas cargas tributárias tendem a impulsionar as empresas tomarem crédito de terceiros objetivando a dedutibilidade de juros na apuração dos tributos sobre o lucro. Este argumento é sustentado no estudo de Pohlmann (2005), o qual apresenta, entre outros, o nível de tributação, o risco empresarial, o tamanho da empresa e o seu nível de crescimento, como um dos principais fatores de endividamento das empresas. Assim, considerando a premissa levantada pela literatura, de que há uma relação entre o planejamento tributário e o nível de endividamento, em virtude da possibilidade de dedução das despesas financeiras no cálculo da base de cálculo dos tributos sobre a renda, bem como o fato das empresas brasileiras enfrentarem grande restrição financeira, conjectura-se a seguinte hipótese de pesquisa.

Hipótese 1a: Há uma relação positiva entre o planejamento tributário [ETR] e o nível de endividamento das empresas listadas na B3.

Para minimizar os riscos inerentes as limitações da ETR, tais como, a influência das compensações de prejuízos de anos anteriores e os incentivos fiscais que influenciam diretamente no valor que será efetivamente desembolsado pelas empresas (Wilkie, 1992; Tang, 2005; Hanlon \& Heitzman, 2010; Paste, 2017), mas não conseguem ser mapeados efetivamente na mensuração da ETR, optou-se por analisar a segunda hipótese.

Hipótese 1b: Há uma relação positiva entre o planejamento tributário [ETR ${ }_{\text {Cash }}$ e o nível de endividamento das empresas listadas na B3.

Nessa perspectiva, supõe-se que as empresas de capital aberto listadas na B3 recorrem a um planejamento tributário mais agressivo a fim de reduzir suas despesas com pagamentos de impostos.

\section{Procedimentos Metodológicos}

\subsection{Caracterização e Amostra da Pesquisa}

Esta pesquisa tem como objetivo investigar o reflexo do planejamento tributário no endividamento das empresas não financeiras listadas na bolsa de valores Brasil Bolsa Balcão 
(B3), no período de 2011 a 2018. A escolha desse intervalo deu-se por ser posterior a publicação do Comitê de Pronunciamentos Contábeis - CPC 32. Este CPC trouxe alterações na forma de apuração dos tributos, logo, prejudicaria a comparabilidade das informações dos valores de tributos sobre lucro entre o período antecedente a esse CPC e o posterior a ele, visto que houve alterações nos parâmetros utilizados, o que poderia afetar o resultado dessa pesquisa. É preciso esclarecer ainda que, pelo fato de algumas variáveis serem defasadas em um ano, somente foi possível analisar os dados a partir do ano de 2011, tendo em vista a adoção das IFRS full no ano de 2010 .

Em relação a amostra, das 477 empresas listadas na B3 no período de 2011 a 2018 contidas na base de dados Thomson Reuters Eikon, foram excluídas todas as instituições financeiras e de fundos de investimento, por apresentarem uma legislação tributária diferenciada em relação aos demais setores, o que não permitiria generalizar os resultados. Foram eliminadas também as companhias que não possuíam dados suficientes para mensuração das variáveis selecionadas no estudo, a saber: um total de 33 entidades da proxy ETR, as quais não possuíam dados suficientes. Além disso, foi necessário fazer a exclusão de 85 empresas da proxy ETRCash, por não possuírem informações suficientes para cálculo da mesma. Nessa perspectiva, o critério adotado foi de manter na base de dados somente aquelas empresas com no mínimo 3 anos de informações, o que ainda possibilitaria o cálculo da variável CashETR. Isso foi feito com o objetivo de não prejudicar a amostra com a redução de um número maior de entidades, restando assim, 236 empresas para ETR e de 184 empresas para a ETRCash.

\subsection{Apresentação do Modelo de Estimação e Descrição e Operacionalização das Variáveis}

Para testar as hipóteses formuladas na pesquisa, foi utilizado como modelo de estimação a Regressão Quantílica (RQ), conforme apresentado nas equações 1 e 2. Tal modelagem tornase adequada para esta investigação em função de algumas características, a saber: (a) mais robusta a outliers que a regressão média; (b) permite estudar o impacto das variáveis independentes em dimensões e localizações diferentes, portanto, proporcionará uma leitura mais precisa dos dados, e; (c) é uma abordagem semiparamétrica, no sentido de que evita hipóteses sobre os erros de regressão em uma distribuição do tipo paramétrica (Cameron; Trivedi, 2009; Araújo, 2017). Segue, na equação 1 e 2, os modelos econométricos.

Hipótese 1a: 


$$
\begin{aligned}
\text { ENDIV }_{i t} & =\beta_{0}+\beta_{1} \text { PT }_{\text {ETRit }}+\beta_{2} \text { ROA }_{i t}+\beta_{3} \text { SIZE }_{i t}+\beta_{4} P P E_{i t}+\beta_{5} \text { MTB } \\
& +\beta_{6} \text { SETORdummy }_{i t}+\beta_{7} \text { PGOVdummy } \\
& +\varepsilon_{i t}
\end{aligned}
$$

(Equação 1)

Hipótese 1b:

$$
\begin{gathered}
\text { ENDIV } i t=\beta_{0}+\beta_{1} \text { PT }_{\text {ETRCashi }}+\beta_{2} \text { ROA }_{i t}+\beta_{3} \text { SIZE }_{i t}+\beta_{4} P P E_{i t}+ \\
\beta_{5} \text { MTB }_{i t}+\beta_{6} \text { SETORdummy }_{i t}+\beta_{7} \text { PGOVdummy } \\
i t
\end{gathered}
$$

(Equação 2)

Em que:

ENDIV $_{\text {it }}$ é a variável dependente, representada pelo endividamento de longo prazo das empresas no ano t.

\begin{tabular}{|c|c|c|c|}
\hline Tipo & Variáveis & Descrição & Cálculo para utilização no modelo \\
\hline $\mathrm{D}$ & ENDIV $_{\text {it }}$ & $\begin{array}{l}\text { Endividamento de Longo } \\
\text { Prazo }\end{array}$ & Dívida de Longo Prazo / Ativo Total do Ano Anterior \\
\hline \multirow{2}{*}{ I } & $\mathrm{PT}_{\text {ETRit }}$ & $\begin{array}{l}\text { Planejamento Tributário } \\
\text { mensurado pela ETR }\end{array}$ & $\begin{array}{l}\text { Variável dummy, sendo } 1 \text { para empresas com ETR menor que } \\
\text { a média do setor e } 0 \text { para empresas com ETR maior que a } \\
\text { média do setor. ETR = Despesa Total de IRPJ e CSLL / Lucro } \\
\text { Antes do Imposto de Renda (LAIR) }\end{array}$ \\
\hline & PT $_{\text {ETRCashit }}$ & $\begin{array}{l}\text { Planejamento Tributário } \\
\text { mensurado pela } \\
\text { ETRCash }\end{array}$ & $\begin{array}{l}\text { Variável dummy, sendo } 1 \text { para empresas com ETRCash menor } \\
\text { que a média do setor e } 0 \text { para empresas com ETRCash maior } \\
\text { que a média da ETR do setor. ETRCash = Total de Tributos } \\
\text { pagos* / Lucro Antes do Imposto de Renda (LAIR) }\end{array}$ \\
\hline \multirow{6}{*}{$\mathrm{C}$} & $\mathrm{ROA}_{\text {it }}$ & Rentabilidade & Lucro operacional / Ativo total do ano anterior \\
\hline & $\mathrm{SIZE}_{\text {it }}$ & Tamanho da Empresa & $\begin{array}{l}\text { Logaritmo natural do total de ativos da empresa no início do } \\
\text { ano }\end{array}$ \\
\hline & $\mathrm{PPE}_{\mathrm{it}}$ & $\begin{array}{l}\text { Intensidade de Capital - } \\
\text { Imobilizado }\end{array}$ & Ativo Imobilizado Líquido/ Ativo total \\
\hline & $\mathrm{MTB}_{\text {it }}$ & Market-to-Book & Valor de Mercado ano t/ Patrimônio líquido ano1 \\
\hline & SETORdummy & Setor de Atuação & $\begin{array}{l}\text { Variável dummy, sendo } 1 \text { para empresas que participam de } \\
\text { determinado setor e } 0 \text { para as demais empresas }\end{array}$ \\
\hline & PGOVdummy & $\begin{array}{l}\text { Participação } \\
\text { Governamental }\end{array}$ & $\begin{array}{l}\text { Variável dummy, sendo } 1 \text { para empresas que tem participação } \\
\text { governamental e } 0 \text { para as demais empresas }\end{array}$ \\
\hline
\end{tabular}

Quanto a descrição das demais variáveis que compõe o modelo econométrico e suas respectivas formas de cálculo, constam na Tabela 1.

Tabela 1 - Variáveis utilizadas na pesquisa

Nota: D: Variável Dependente; I: Variável Independente; C: Variável de Controle; *Total dos pagamentos de Imposto de Renda (IRPJ) e Contribuição social (CSLL) desembolsado pela firma i no período t, mas também acumulado para a empresa i no período de 9 anos, a partir do período t- 8 até t.

As variávéis de interesse deste estudo são aquelas representativas do Planejamento Tributário mensuradas pela ETR (PTETRit) e ETRCash (PTETRCashit), as quais foram calculadas conforme cálculo apresentado no Tabela 1 e posteriormente transformadas em variáveis 
dummies, seguindo a metodologia utilizada por Araújo e Leite (2019). Atribuiu o valor 1 (um) para as empresas classificadas com "Planejamento Tributário Agressivo" e 0 (zero) para empresas classificadas com "Planejamento Tributário Moderado". Essa atribuição leva em consideração o seguinte parâmetro: i) as empresas que apresentarem os valores da ETR e ETRCash menores que a média da ETR do setor foram classificadas com "Planejamento Tributário Agressivo"; e, ii) nos casos em que os valores forem iguais ou maior que a média do setor serão classificadas com "Planejamento Tributário com Agressividade Moderada". Conforme discutido no referencial, observa-se que o contexto tributário enfrentado pelas empresas brasileiras é pautado na sobrecarga de impostos e na complexidade da legislação fiscal, o que acaba estimulando as empresas adotarem estratégias de planejamento tributário. Nesses termos, o presente trabalho leva em consideração os achados de Stickney e McGee (1982), Graham e Tucker (2006), Chen et al. (2010), Badertscher, Katz e Rego (2013), Chyz, Leung, Li e Rui (2013) e Bauer, Fang, Pittman, Zhang e Zhao (2015), os quais identificaram uma relação direta entre o nível de alavancagem com níveis mais elevados de planejamento fiscal. Reforçando, Katz, Khan e Schmidt (2013) expõem que empresas agressivas tributariamente têm significativamente mais dívidas do que as empresas que não são.

A variável $\mathrm{ROA}_{\text {it }}$ é utilizada para representar a rentabilidade das empresas. De acordo com Medeiros e Daher (2008), quanto maior a lucratividade das instituições, mais elas se endividam, reduzindo assim a carga tributária devido a dedutibilidade dos juros. Nesse sentido, os autores Chen et al. (2010), Pohlmann e Iudícibus (2010) e Parente (2011), afirmam que maiores níveis de endividamento tendem a sinalizar estratégias das companhias para reduzir o valor de tributos pagos sobre o lucro, proporcionando assim, maiores retornos aos acionistas. Pelo exposto, segue o posicionamento de Damodaran (2004) e Assaf Neto (2013), os quais afirmam que, em virtude do ROA mensurar a eficiência operacional da empresa, ele se torna um indicador muito importante de rentabilidade. Por isso e considerando a perpectiva de Sant'Ana (2001), que identificou uma relação positiva de significativa entre as variáveis rentabilidade e o endividamento, utilizou-se o ROA como variável de controle nesta pesquisa.

O tamanho da empresa $\left(\mathrm{SIZE}_{\mathrm{it}}\right)$ representa uma proxy importante a ser analisada, visto que foram encontradas na literatura, a existência de uma relação entre o tamanho da empresa e o seu endividamento. Segundo Barclay e Smith (1995), as grandes empresas são as que emitem um maior número de dívidas de longo prazo. Para Rajan e Zingales (1995), entidade com maior tamanho tendem a não falharem com freqüência, com isso, o tamanho se torna uma proxy inversamente proporcional à probabilidade de falência da entidade. Deste modo, o tamanho tem 
um impacto positivo na obtenção de dívidas de longo prazo, relacionada diretamente com a continuidade da empresa.

A variável Intensidade de Capital ( $\left.\mathrm{PPE}_{\mathrm{it}}\right)$ é utilizada em estudos que abordam a redução do endividamento das empresas por meio do planejamento tributário. Isso ocorre porque, muitos incentivos fiscais concedidos pelo governo estão relacionados aos ativos fixos depreciáveis das empresas, o que pode resultar em um menor desembolso no pagamento de tributos (Santos et al., 2013; Fernández-Rodríguez \& Martínez-Arias, 2014; Lazăr, 2014). Inclusive, desde o trabalho de Modigliani e Miller (1963), já se admitia a influência dos benefícios fiscal gerados pelo endividamento na estrutura de capital das empresas. Logo, espera-se que haja uma relação positiva entre a intensidade de imobilização do capital e o nível de endividamento.

Uma outra variável de controle considerada nesse estudo é o índice Market-to-Book $\left(\mathrm{MTB}_{\mathrm{it}}\right)$. De acordo com os estudos de Paste (2017), empresas mais eficientes conseguem maximizar os resultados oriundos de planejamento tributário, devido ao fato de elevarem sua receita operacional em detrimento aos custos, fato que, segundo Perez e Martins (2005), impulsiona o crescimento do valor da empresa. Diante disso, espera-se uma relação positiva entre o $\mathrm{MTB}_{\mathrm{it}}$ e o nível de endividamento das empresas, uma vez que, as empresas com maiores oportunidades de crescimento necessitam de fundos que, muitas vezes, não são, suficientemente, gerados pelos lucros retidos, bem como, estas empresas devem aumentar seu grau de alavancagem financeira para limitar a autonomia ou a liberdade dos gestores (Bastos \& Nakamura, 2009).

A variável SETORdummy foi incluída tendo em vista que diferentes cargas tributárias podem ser decorrentes de tratamentos fiscais diferentes dados a determinados setores (Derashid \& Zhang, 2003), visto que alguns setores econômicos são incentivados por benefícios físcais específicos, interferindo na maneira como as empresas empregaram seu capital (Santos et al., 2013). Ademais, de acordo com Aggarwal (1994), o setor industrial e o país de origem da empresa são fatores significativos na explicação do nível de endividamento adotado pela empresa. Vale salientar que a identificação dos setores das empresas tomou como base na classificação estabelecida pelo The Global Industry Classification Standard (GICS), disponível na base de dados Thomson Reuters Eikon, a saber: Materiais Básicos, Consumo Cíclico, Consumo Cíclico, Consumo não-Cíclico, Energia, Assistência Médica, Bens Industriais, de Construção e de Transporte, Tecnologia da Informação, Telecomunicações e Utilidade Pública.

E por fim, foi inserida a variável de controle PGOVdummy que representa a presença da participação governamental na estrutura de propriedade das empresas. Segundo Terra 
(2007), a estrutura de capital das empresas pode afetar na obtenção de créditos com terceiros. Os autores enfatizam que, as empresas estatais ou aquelas que participam de conglomerados industriais ou ainda as subsidiárias de grandes corporações multinacionais, normalmente não enfrentam problemas para obtenção de crédito, visto que possuem uma probabilidade mais baixa de falência, sendo assim, torna-se uma proxy importante na determinação do endividamento. Diante disso, espera-se que empresas com participação governamental possuam maior nível de endividamento.

\section{Análise dos Resultados}

\subsection{Análise Descritiva das Variáveis Dependente e Independentes}

De acordo com a Tabela 2, o endividamento (ENDIV) das empresas com planejamento tributário agressivo apresentou uma média de 0,4559 , enquanto as empresas com planejamento tributário moderado obtiveram uma média de 0,3336. Com isso, percebe-se que as empresas mais endividadas são aquelas que se utilizam de práticas de planejamento fiscal mais agressivas. Isso significa que as empresas com maiores níveis de endividamento possuem menores taxas de tributação, corroborando com a trade-off theory, a qual prevê que as empresas tendem a aumentar o endividamento em busca de uma estrutura ótima de capital, para usufruir do benefício fiscal da dívida e consequentemente pagar tributos menores sem incorrer em riscos de falência (Myers, 1984). Contudo, destaca-se ainda, que as empresas mais agressivas demonstraram uma maior dispersão da média em relação à mediana, uma vez que o desviopadrão foi 3,1280, evidenciando que existem nessa amostra empresas com níveis de endividamento distantes da média.

Tabela 2 - Estatística Descritiva das Variáveis Dependente e Independentes (2011 a 2018)

\begin{tabular}{c|cccc|cccc}
\hline Nível & \multicolumn{2}{|c|}{ Com Planejamento Tributário Moderado } & \multicolumn{4}{c}{ Com Planejamento Tributário Agressivo } \\
Variável & Observações & Média & Mediana & DP & Observações & Média & Mediana & DP \\
\hline ENDIV & 848 & 0,3336 & 0,1942 & 2,1822 & 926 & 0,4559 & 0,1812 & 3,1280 \\
ETR & 848 & 0,7135 & 0,3123 & 4,0017 & 926 & 0,8951 & 0,0761 & 1,3600 \\
ETRCash & 533 & 14,8766 & 0,6396 & 84,5853 & 776 & $-7,6938$ & 0 & 66,1749 \\
\hline
\end{tabular}

Nota: ENDIV: Endividamento; ETR: Taxa Efetiva de Tributação; ETRCash: Taxa de Tributação Pagos

No tocante a variável independente $\mathrm{ETR}_{\mathrm{it}}$, as empresas com planejamento tributário moderado apresentaram uma média de 0,7135 e as empresas com planejamento tributário agressivo uma média de 0,8951 . No primeiro caso, as entidades demonstraram um desvio padrão de 4,0017 e uma mediana de 0,3123 , enquanto o grupo de empresas com planejamento 
tributário agressivo o desvio padrão foi de 1,3600 e mediana de 0,0761. Nota-se, com isso, que a taxa efetiva de tributos do primeiro grupo possui uma distribuição com valores discrepantes entre si, o que pode justificar a utilização da regressão quantílica como método de análise inferencial neste estudo.

Na sequência, ao observar a ETRCash ${ }_{\text {it, }}$, verifica-se um contraste no comportamento à variável ETR, visto que, a média dos tributos pagos pelas empresas com planejamento tributário moderado foi superior $(14,8766)$ a média registrada àquelas com planejamento tributário agressivo (-7,6938). Todavia, a discrepância do desvio padrão seguiu a mesma direção da ETR, uma vez que apresentou os valores de 84,5853 e 66,1749, respectivamente.

Vale ressaltar que essa análise não levou em consideração as especificidades do setor econômico do qual a empresa faz parte. No entanto, para categorizar o grupo de empresas em função do tipo de planejamento, seguiu a metodologia utilizada no trabalho de Araújo e Leite (2019), em que as empresas que possuíam a ETR e ETRCash abaixo da ETR média do setor foram consideradas com planejamento tributário agressivo, caso contrário, as empresas que possuíam a ETR e ETRCash igual ou acima da média do setor foram consideradas com planejamento tributário moderado. A seguir, constam as médias setoriais da ETR, as quais serviram como parâmetro para realizar a categorização.

Tabela 3 - Média da ETR por Setor (2011 a 2018)

\begin{tabular}{lcc}
\hline \multicolumn{1}{c}{ Setor } & Média & Quantidade de observações por setor \\
\hline Materiais Básicos & 0,0955 & 227 \\
Consumo Cíclico & 0,1914 & 388 \\
Consumo não-Cíclico & 0,0340 & 253 \\
Energia & 0,1892 & 61 \\
Assistência Médica & 0,3232 & 86 \\
Bens Industriais, de Construção e de Transporte & 0,3653 & 314 \\
Tecnologia da Informação & 0,1942 & 49 \\
Telecomunicações & 0,1551 & 31 \\
Utilidade Pública & 0,6834 & 365 \\
\hline \multicolumn{2}{c}{ Média } & $\mathbf{0 , 2 9 4 4}$ \\
\hline
\end{tabular}

Conforme Tabela 3, a média geral da ETR no período de 2011 a 2018 foi de 29,44\%, no quantitativo de 1774 observações. Os setores de Utilidade Pública e Bens Industriais, de Construção e de Transporte foram os que apresentaram maior média, representados respectivamente por 68,34\%, 36,53\%, taxa acima da alíquota nominal do IRPJ e CSLL de 34\%. Por outro lado, os setores que demonstraram menor ETR foram o de Consumo não-cíclico, com 3,40\% e Materiais Básicos, com 9,55\%. 


\subsection{Análise das Estimações dos Modelos Econométricos}

Para análise inferencial dos dados, utilizou-se regressão quantílica, a qual permite a análise de toda a distribuição condicional da variável resposta e não está sujeita a influências de valores extremos da variável dependente (KOENKER, 2005). Nesse sentido, a finalidade foi de solucionar o problema da presença de heterocedasticidade, identificada após o teste Wald.

\subsubsection{Planejamento tributário mensurado a partir da ETR}

Considerando o resultado destacado na Tabela 4, observa-se que apenas no quantil 25, onde estão inseridas as empresas que possuem menores níveis de endividamento de longo prazo, apresentou significância estatística ao nível de 5\% com a variável planejamento tributário (PT $\mathrm{PTRit}_{\mathrm{t}}$ ) e um coeficiente negativo $(-0,0174)$. Ou seja, em níveis mais baixos de endividamento, as empresas com práticas de planejamento tributário agressivo são 1,74\% menos endividadas do que aquelas de planejamento tributário moderado.

Constata-se ainda que, em níveis mais elevados de endividamento, o valor preditivo do planejamento tributário não pôde ser identificado, haja vista que a variável $\mathrm{PT}_{\mathrm{ETRit}}$ não apresentou significância estatística nos quantis 50 e 75. Este resultado contraria os estudos de Katz et al. (2013) e Chyz et al. (2013), os quais expõem que empresas agressivas tributariamente têm significativamente mais dívidas do que as empresas que não são; também vai de encontro ao que é preconizado pela trade-off theory, que prevê o aumento no endividamento com vista a uma estrutura ótima de capital para obtenção do benefício fiscal da dívida e por conseguinte incorrer em menos tributos (Myers, 1984).

Tabela 4 - Resultado Estatístico do Planejamento Tributário (PT $\mathrm{PTR}_{\mathrm{ETR}}$ ) e Endividamento (2011 a 2018)

\begin{tabular}{|c|c|c|c|c|c|c|}
\hline \multirow{2}{*}{ Variáveis } & \multicolumn{6}{|c|}{ Regressão Quantílica } \\
\hline & Quantil 25 & P-valor & Quantil 50 & P-valor & Quantil 75 & P-valor \\
\hline PT $_{\text {ETRit }}$ & $-0,0174$ & 0,0330 & $-0,0120$ & 0,2200 & $-0,0173$ & 0,1710 \\
\hline $\mathrm{ROA}_{\mathrm{it}}$ & $-0,0004$ & 0,9670 & $-0,0003$ & 0,9900 & $-0,0001$ & 0,9980 \\
\hline $\mathrm{PPE}_{\text {it }}$ & 0,0687 & 0,0020 & 0,1134 & 0,0000 & 0,1679 & 0,0000 \\
\hline SIZE $_{i t}$ & 0,0296 & 0,0000 & 0,0359 & 0,0000 & 0,0355 & 0,0000 \\
\hline MTB $_{\text {it }}$ & 0,0010 & 0,2410 & 0,0009 & 0,3380 & 0,0003 & 0,9090 \\
\hline PGOVdummy & $-0,0511$ & 0,0000 & $-0,0561$ & 0,0050 & 0,0002 & 0,9910 \\
\hline SETORdummy & \multirow{2}{*}{\multicolumn{2}{|c|}{$\begin{array}{c}\text { SIM } \\
-.482215\end{array}$}} & \multicolumn{2}{|c|}{ SIM } & \multirow{2}{*}{\multicolumn{2}{|c|}{$\begin{array}{c}\text { SIM } \\
-.4374009\end{array}$}} \\
\hline$\beta 0$ & & & -.54 & & & \\
\hline Observações & \multirow{2}{*}{\multicolumn{2}{|c|}{$\sec$}} & \multicolumn{2}{|c|}{1.754} & \multirow{2}{*}{\multicolumn{2}{|c|}{0,0449}} \\
\hline Pseudo $\mathrm{R}^{2}$ & & 0,0669 & \multicolumn{2}{|c|}{0,0721} & & \\
\hline
\end{tabular}

Diante disso, conclui-se que, houve a rejeição da Hipótese 1a (Há uma relação positiva entre o planejamento tributário [ETR] e o nível de endividamento das empresas listadas na B3), 
em todos os quantis de distribuição da Regressão Quantílica. Ou seja, empresas com planejamento tributário mais agressivos, quando considerada a ETR praticada pelas mesmas, implica em menor nível de endividamento oneroso, sobretudo no quantil 25 , onde o coeficiente $(-0,0174)$ apresentou a maior relação negativa entre as variáveis PTETRit $_{\text {e }}$ ENDIV $_{\text {it, }}$ além de ter sido o único quantil com significância estatística na relação.

No entanto, essas evidências contraria os trabalhos de Chen et al. (2010), Kraft (2014) e Ramalhosa (2015), os quais apontaram uma relação negativa entre planejamento tributário (utilizada proxy ETR) e o endividamento. Estes autores confirmaram que quanto maior a despesa com tributo, mais endividada a empresa será. Ademais, as práticas mais agressivas de planejamento tributário, para além de certo nível, poderão produzir resultados contabilísticos e/ou fiscais negativos, caracterizando, dessa forma, um comportamento típico de evasão fiscal (Parente, 2011). Por esta razão, as organizações costumam determinar o nível de agressividade fiscal, a partir do trade-off entre os benefícios e os custos marginais de gerenciar os tributos (Chen et al., 2010), como mencionado pela trade-off theory. Outrora, Modigliani e Miller (1963) ao discorrer sobre a teoria da irrelevância dos dividendos, já defendia o argumento de que, se há Imposto de Renda creditado no resultado proveniente de despesas financeiras, a estrutura de capital ótima tende ao endividamento até o ponto onde os custos do endividamento superem os seus benefícios.

Em relação às variáveis de controle, observou-se que a rentabilidade $\left(\mathrm{ROA}_{\mathrm{it}}\right)$ não possui valor preditivo que justifique o nível de endividamento das companhias brasileiras durante o período investigado, em nenhum dos quantis de distribuição, indo de encontro aos resultados encontrados por Sant'Ana (2001) e Daher (2004), que além de identificar significância estatística entre essas variáveis, verificou uma relação direta entre elas. Estes, partem do pressuposto que as empresas mais rentáveis se endividam mais, como alternativa de reduzir os custos tributários a partir da dedutibilidade dos juros.

Na sequência, nota-se que a Intensidade de Capital - Imobilizado ( $\left.\mathrm{PPE}_{\mathrm{it}}\right)$ apresentou uma relação positiva e significante com a variável endividamento $\left(\mathrm{ENDIV}_{\mathrm{it}}\right)$, em todos os quantís, cujo coeficientes foram, respectivamente, 0,0687 (quantil 25), 0,1134 (quantil 50) e 0,1679 (quantil 75), todos a um nível de significância de 1\%. Ressalta-se, ainda, que as empresas mais endividadas apresentam maiores investimentos em capital imobilizado, corroborando com Fernández-Rodríguez e Martínez-Arias (2014), que identificaram uma influência significativamente positiva entre essas variáveis, ao analisarem a realidade das empresas brasileiras e chinesas. Ademais, as empresas que compõem a amostra desta pesquisa possuem uma legislação tributária que permite a dedutibilidade da depreciação em suas 
estratégias tributárias, favorecendo, assim, a prática de planejamento tributário mais agressivo, por meio de investimentos em ativos imobilizado.

Pôde-se evidenciar, também, uma relação de significância direta do endividamento com o tamanho da empresa (SIZE $\mathrm{it}_{\mathrm{i}}$ ), ao nível de 1\% em todos os quantis, cujos coeficientes foram, respectivamente, 0,0296 (quantil 25), 0,0359 (quantil 50) e 0,0355 (quantil 75). Entende-se, com isso, nos quantis mais elevados, as empresas maiores tendem a se endividarem aproximadamente $35 \%$ a mais do que as empresas menores. Esse resultado corrobora com com a compreensão de Silva e Maciel (2014), que acreditam que o Governo pode imputar uma regulamentação mais rígida ou, até mesmo, aumentar os tributos do setor, se identificar uma potencial fonte de recolhimento de impostos. Assim, quanto maior for o tamanho da firma, maior será os impostos devidos (Bispo, Calijuri \& Lima, 2009; Chyz et al., 2013).

No que se refere a variável Market-to-Book ( $\mathrm{MTB}_{\mathrm{it}}$ ), não foi possível verificar significância estatística com o endividamento de longo prazo em nenhum dos quantís, indo de encontro à pesquisa de Bastos e Nakamura (2009), cujo resultado evidenciou que, as empresas recorrem ao endividamento de longo prazo dado o potencial de crescimento delas.

Por fim, observou-se uma relação de significância inversa do endividamento com o a participação governamental (PGOVdummy), ao nível de 1\%, nos quantis 25 e 50, cujos coeficientes foram, respectivamente, 0,0511 (quantil 25) e -0,0561 (quantil 50). Diante disso, infere-se que o grupo de empresas classificadas "Com Planejamento Tributário Agressivo", em níveis medianos e mais baixos de endividamento sofrem maior influência negativa da participação governamental do que as empresas "Com Planejamento Tributário Moderado". Contrastando esse resultado, Mamede, Nakamura, Nakamura, Jones e Jardim (2017) identificou que as empresas de economia mista apresentam níveis maiores de endividamento que as empresas privadas. Por outro lado, converge com a explicação de Lopes (2012), que as maiores empresas são mais bem fiscalizadas pelas autoridades, como é o caso dessas companhias; e, nesse caso, a prática de planejamento tributário mais agressivo pode ser vista como uma tentativa de realizar evasão fiscal, gerando assim, um conflito de interesse entre os acionistas e o governo.

\subsubsection{Planejamento tributário mensurado a partir da ETRCash}

Levando-se em consideração os dados apresentados na Tabela 5, nota-se que a variável planejamento tributário ( $\left.\mathrm{PT}_{\mathrm{ETR} \text { cash }}\right)$ apresentou significância estatística somente no quantil 25 , ao nível de 5\%, e coeficiente positivo de 0,0330 . Ou seja, em níveis mais baixos de 
endividamento, as empresas "Com Planejamento Tributário Agressivo" são 0,52\% mais endividadas do que aquelas "Com Planejamento Tributário Moderado". Constata-se ainda que, em níveis mais elevados de endividamento, o valor preditivo do planejamento tributário não

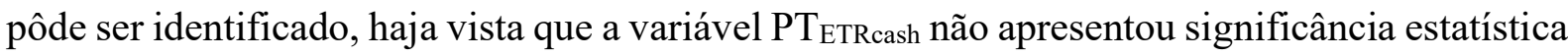
nos quantis 50 e 75 .

Tabela 5 - Resultado Estatístico do Planejamento Tributário (PT $\mathrm{PTR}_{\mathrm{E} \text { cash }}$ ) e Endividamento (2011 a 2018)

\begin{tabular}{|c|c|c|c|c|c|c|}
\hline \multirow{2}{*}{$\begin{array}{c}\text { Variáveis } \\
\text { ENDIV }\end{array}$} & \multicolumn{6}{|c|}{ Regressão Quantílica } \\
\hline & Quantil 25 & P-valor & Quantil 50 & P-valor & Quantil 75 & P-valor \\
\hline PT $_{\text {ETRCashit }}$ & 0,0052 & 0,0330 & 0,0048 & 0,9930 & $-0,0978$ & 0,8900 \\
\hline $\mathrm{ROA}_{\mathrm{it}}$ & $-0,0784$ & 0,9670 & $-0,3180$ & 0,9880 & $-3,4766$ & 0,8950 \\
\hline $\mathrm{PPE}_{\mathrm{it}}$ & 0,1039 & 0,0020 & 0,1657 & 0,7210 & $-0,0294$ & 0,9750 \\
\hline SIZE $_{i t}$ & 0,0265 & 0,0000 & 0,0339 & 0,8660 & $-0,0294$ & 0,8230 \\
\hline $\mathrm{MTB}_{\text {it }}$ & 0,0003 & 0,2410 & $-0,0002$ & 0,9980 & 0,0013 & 0,9930 \\
\hline PGOVdummy & $-0,0503$ & 0,0000 & $-0,0552$ & 0,8950 & $-0,1264$ & 0,9020 \\
\hline SETORdummy & \multirow{3}{*}{\multicolumn{2}{|c|}{$\begin{array}{c}\text { SIM } \\
-.3983407\end{array}$}} & \multirow{2}{*}{\multicolumn{2}{|c|}{$\begin{array}{c}\text { SIM } \\
-.4545313\end{array}$}} & \multirow{2}{*}{\multicolumn{2}{|c|}{$\begin{array}{c}\text { SIM } \\
-.1387525\end{array}$}} \\
\hline$\beta 0$ & & & & & & \\
\hline Observações & & & \multirow{2}{*}{\multicolumn{2}{|c|}{$\begin{array}{c}1.315 \\
0.0107\end{array}$}} & \multirow{2}{*}{\multicolumn{2}{|c|}{0.0190}} \\
\hline Pseudo $\mathrm{R}^{2}$ & \multicolumn{2}{|c|}{0.0100} & & & & \\
\hline
\end{tabular}

Os resultados são consistentes com as estimativas obtidas nos estudos de Pohlmann e Iudícibus (2010) e Santos et al. (2013), os quais averiguaram que empresas com altos índices de endividamento apresentam baixa tributação sobre o lucro, o que sugere práticas mais agressivas de planejamento tributário. Um dos fatores responsáveis por esse endividamento são os juros passivos oriundos de empréstimos, os quais são utilizados como uma estratégia de planejamento tributário para abatimento do imposto incidente sobre o lucro. Logo, há uma relação direta entre o nível de alavancagem com níveis mais elevados de planejamento físcal (Bauer et al., 2015).

Diante disso, conclui-se que, apenas no quantil 25 não se rejeita a Hipótese 1b (Há uma relação positiva entre o planejamento tributário [ETRCash] e o nível de endividamento das empresas listadas na B3). Ou seja, empresas com planejamento tributário mais agressivos apresentam um nível de endividamento oneroso superior àquelas com planejamento tributário moderado, quando considerado os tributos efetivamente pagos, contudo, a significância estatística dessa relação não se matém em níveis mais elevados de endividamento. Argumentase que tais evidências empíricas podem estar alinhadas com a pecking order theory, a qual explica que as empresas seguem uma hierarquia quanto as suas fontes de financiamento, recorrendo primeiro aos lucros retidos, em seguida ao endividamento junto a terceiros e, por último, a emissão de novas ações (Myers,1984). Sendo assim, empresas com difentes estruturas de capitais podem apresentar determinantes diferentes para essa condição de menos ou mais 
endividadadas, como pode ser comprovado por meio dos resultados desse estudo, em que apenas as empresas com menores níveis de endividamento apresentaram relação significativa com o planejamento tributário mais agressivo. Ademais, segundo Balakrishnan e Fox (1993), uma outra justificativa para esse resultado é que o sinal e a significância dessa relação dependem dos indicadores utilizados na sua medição; bem como o setor de atuação e país de origem da empresa (Aggarwal, 1994).

Assim como verificado no modelo que considerou $\mathrm{PT}_{\mathrm{ETR}}$, não foi possível encontrar significância estatística entre a rentabilidade $\left(\mathrm{ROA}_{\mathrm{it}}\right)$ e o endividamento $\left(\mathrm{ENDIV}_{\mathrm{it}}\right)$, quando analisado o planejamento tributário por meio da ETRCash (PTETRCashit). Semelhante, a variável Market-to-Book $\left(\mathrm{MTB}_{\mathrm{it}}\right)$ também não apresentou significância estatística em nenhum dos quantís, o contrastou com as evidências observadas por Kayo, Patrocínio e Martin (2009), de que o endividamento exerce um papel muito importante na geração de valor das empresas.

Em relação a variável Intensidade de Capital - Imobilizado $\left(\mathrm{PPE}_{\mathrm{it}}\right)$, foi obtida uma relação de significância somente no quantil 25, ao nível de $1 \%$. Inferindo, assim, nos níveis mais baixos de endividamento, as empresas que realizam planejamento tributário agressivo apresentam 10,39\% mais investimento em capital imobilizado do que as empresas com planejamento tributário moderado. A respeito disso, Chen et al. (2010) esclarecem que quanto maior o investimento em ativos depreciáveis, menor serão os custos com impostos. Pois, de acordo com Rego e Wilson (2012), os benefícios de posições fiscais mais agressivas significam, simultaneamente, redução de obrigações fiscais e o aumento do fluxo de caixa e lucro líquido após impostos. Por outro lado, percebe-se que o valor preditivo da variável PPE em relação ao nível de endividamento das empresas, não se mantém nos quantis 50 e 75 .

No tocante ao tamanho da empresa $\left(\mathrm{SIZE}_{\mathrm{it}}\right)$, nota-se um resultado convergente ao analisado anteriormente (na Tabela 4), mas somente no quantil 25, cuja significância estatística ocorreu ao nível de $1 \%$ e o coeficiente positivo de 0,0265 . Entende-se, com isso, no quantil 25 , as empresas maiores tendem a se endividarem aproximadamente $2,65 \%$ a mais do que as empresas menores. Barbosa (2010), verificou um resultado análogo, afirmando que as empresas maiores tendem a ser as que apresentam os maiores níveis de endividamento. Na sequência, analisando a participação governamental (PGOVdummy), percebe-se que ela apresentou significância estatística apenas no quantil 25 , ao nível de $1 \%$, e coeficiente negativo de $-0,0503$. Este resultado se assemelha àquele analisado anteriormente (na Tabela 3), em que contrasta a pesquisa de Mamede et al. (2017), em que se deparou com uma relação positiva e significante entre a participação governamental o endividamento. 
Assim, os resultados demonstram que a estratégia de gestão das empresas é o principal fator de direcionamento de suas práticas tributárias, sobretudo, naquelas que estão inseridas nos níveis mais baixos de endividamento, em que apresentam relações de significância diferentes, quando mensurado o planejamento tributário por meior das proxys da ETR (apresentou coeficiente negativo) e da ETRCash (apresentou coeficiente positivo), podendo essa divergência ser originária de estratégias de geração de fluxo de caixa da empresa. Tal perspectiva também pode ser esclarecida sob a luz da pecking order theory, tendo em vista as empresas utilizam diferentes práticas tributárias e isso também pode propiciar estruturas de capitais diferentes que sejam mais adequadas aos seus objetivos.

\section{Considerações Finais}

Este trabalho teve como objetivo investigar o reflexo do planejamento tributário no endividamento das empresas não financeiras listadas na B3 no período de 2011 a 2018. Para isso, utilizou-se o método de Regressão Quantílica para estimação dos modelos e duas proxies para caracterizar o Planejamento Tributário, sendo elas: a taxa efetiva de tributação (ETR) e a taxa efetiva de tributação desembolsada (ETRCash).

O resultado observado sob a perspectiva da ETR mostra que no menor quantil (quantil 25), as empresas mais agressivas fiscalmente são menos endividadas do que as empresas que adotam planejamento tributário moderado. $\mathrm{O}$ que pode ser justificado pela preocupação dessas entidades está em gerar benefícios a empresa por meio da redução dos tributos, até o limite em que os custos advindos com esse planejamento não se tornem maiores que os seus benefícios, logo, tendem a adotarem planejamento tributários mais conservador. Ou seja, optam por arcar com uma maior carga tributária do que ariscar serem atuadas em práticas que os órgãos fiscalizadores e demais stakeholders, compreendam como práticas que permeiam ações de evasão fiscal. Por outro lado, sob a perspectiva da ETR Cash, embora a evidência de um coeficiente muito baixo, observou-se que as práticas de planejamento fiscal agressiva estão diretamente associadas ao nível de endividamento das empresas inseridas nos quantis menores, o que pode estar associado ao defendido pela pecking order theory, sobre a ordem de preferência das fontes de financiamento. Com isso, acredita-se que tais empresas, mesmo não sendo favorecidos com altos créditos com terceiros, se utilizam da aquisição de dívida onerosa como estratégia para se beneficiar do abatimento dos juros passivos sobre o lucro tributável. Contudo, essa relação não se perdura nos quantis em que se concentra os níveis mais elevados de endividamento (quantil 50 e 75).

Revista Gestão e Secretariado (GeSec), São Paulo, SP, 12(2), maio/ago., 2021, 225-252. 
Por fim, vale ressaltar que os resultados controversos verificados nesta pesquisa, possivelmente, ocorreram em virtude da falta de um método adequado de captação das diversas relações que envolvem o planejamento tributário, tais como isenções, deduções e créditos fiscais. Como também, é imprescindível destacar que a escolha por determinado estratégia de planejamento tributário ocorre em função do trade-off entre os benefícios e os custos marginais de gerenciar os tributos, pois, se de um lado o planejamento tributário implica em um aumento dos fluxos de caixa das empresas após os impostos, do outro lado têm os custos implícitos nesse processo, que, muitas vezes, pode passar despercebidos ou ser negligenciado pelos tomadores de decisão. Vale salientar ainda, que os resultados do presente estudo foram capazes de propiciar uma análise paralela com as teorias que exploram as estruturas de capitais das empresas, quais sejam: teoria da irrelevância dos dividendos, pecking order theory e trade-off theory. A partir de tais considerações foi possível verificar que essas teorias não são excludentes e podem explicar diversas evidências empíricas a respeito dos níveis de endividamento, como por exemplo os resultados desta pesquisa.

Dentre as limitações que, provavelmente, interferiram no desenvolvimento desta pesquisa estão: (a) escolha das proxies utilizadas na mensuração do planejamento tributário; (b) limitações das variáveis empregadas no modelo estatístico e/ou ausência da variável de controle de instabilidade econômica e política do país durante o período analisado; (c) particularidades setoriais; entre outros aspectos. Como proposta para futuras pesquisas, propõe-se verificar as limitações acima descritas, bem como abranger as novas mudanças advindas com a lei 13.670/18, que determinou que não podem ser objeto de compensação os débitos relativos ao recolhimento mensal por estimativa do IRPJ e da CSLL, fato que, provavelmente, reduz muitas diferenças entre as análises das variáveis ETR e ETRCash.

\section{Referências}

Aggarwal, R. (1994). International differences in capital structure norms: an empirical study of large European companies. MIR: Management International Review, 34, 5-18.

Araújo, R. A. de M. (2017). Reflexo do nível de agressividade fiscal sobre a rentabilidade de empresas listadas na BM\&FBOVESPA e NYSE. Dissertação de mestrado. João Pessoa, PB, Brasil. 
Araújo, R. A. de M., \& Leite, P. A. M., Fo. (2019). Reflexo do nível de agressividade físcal sobre a rentabilidade de empresas listadas na B3 e NYSE. Revista Universo Contábil, 14(4), 115-136.

Armstrong, C. S., Blouin, J. L., \& Larcker, D. F. (2011). The Incentives for Tax Planning. Journal of Accounting and Economics, 53(1), 391-411.

Assaf, A., Neto. (2013). Curso de administração financeira. São Paulo: Atlas.

Badertscher, B., Katz, S. P., \& Rego, S. O. (2013). The separation of ownership and control and corporate tax avoidance. Journal of Accounting and Economics, v. 56, n. 2-3, p. $228-$ 250,2013

Balakrishnan, S., \& Fox, I. (1993). Asset specificity, firm heterogeneity and capital structure. Strategic Management Journal, 14(1), 3-16.

Barbosa, A. C. (2010). Estrutura de capital e fatores determinantes do endividamento: um estudo do setor de energia elétrica brasileiro no ano de 2007. Dissertação de Mestrado, Brasília, DF, Brasil.

Barclay, M. J., \& Smith Jr, C. W. (1995). The maturity structure of corporate debt. the Journal of Finance, 50(2), 609-631.

Bastos, D. D., \& Nakamura, W. T. (2009). Determinantes da estrutura de capital das companhias abertas no Brasil, México e Chile no período 2001-2006. Revista Contabilidade \& Finanças - USP, 20 50), 75-94.

Bauer, A. M., Fang, J., Pittman, J., Zhang, Y., \& Zhao, Y. (2015). The importance of aggressive tax planning to the diversion of corporate resources: Evidence from Chinese public firms. $\begin{array}{llll}\text { Retrieved November, } & \text { 16, 2019, from }\end{array}$ https://papers.ssrn.com/sol3/papers.cfm?abstract id=2586818

Bispo, J. S, Calijuri, M. S. S., Casella, B., \& Lima, I. S. (2009). A importância dos dados contábeis para a relação entre carga tributária, tamanho e setor econômico das empresas brasileiras. RIC - Revista de Informação Contábil. 3(3), 25-43.

Blouin, J. (2014). Defining and Measuring Tax Planning Aggressiveness. National Tax Journal, 67(4), 875-900.

Brito, R. D., \& Lima, M. R. (2005). A escolha da estrutura de capital sob fraca garantia legal: o caso do Brasil. Revista Brasileira de Economia, 59(2), 177-208. 
Cameron, A. C., \& Trivedi, P. K. (2009). Microeconometrics using stata. College Station, TX: Stata press, 23(4), 1-6.

Carpes, A., \& Frederico, C. (2018). Análise bibliometrica da produção científica brasileira sobre planejamento tributário. Recuperado em 15 de janeiro, 2020, de https://rd.uffs.edu.br/bitstream/prefix/2626/1/FREDERICO.pdf

Cerize, N. M. F. (2017). A influência da estrutura de controle na agressividade fiscal. Dissertação de mestrado. Vitória, ES, Brasil.

Chen, S., Chen, X., Cheng, Q., \& Shevlin, T. (2010). Are family firms more tax aggressive than non-family firms? Journal of Financial Economics, 95(1), 41-61.

Chiachio, V. F. O., \& Martinez, A. L. (2019). Efeitos do Modelo de Fleuriet e Índices de Liquidez na Agressividade Tributária. Revista de Administração Contemporânea, 23(2), 160-181.

Chyz, J. A., Leung, W. S. C., Li, O. Z., \& Rui, O. M. (2013). Labor unions and tax aggressiveness. Journal of Financial Economics, 108(3), 675-698.

Cloyd, C. B., Pratt, J., \& Stock, T. (1996). The use of financial accounting choice to support aggressive tax positions: Public and private firms. Journal of Accounting research, 34(1), $23-43$.

Correia, A. G., \& de Moura Ganzarolli, T. F. (2019). Endividamento e Alavancagem Financeira. Id on Line Revista Multidisciplinar e de Psicologia, 13(43), 593-613.

Daher, C. E. (2004). Testes empiricos de Teorias Alternativas sobre a Determinação da Estrutura de Capital das Empresas Brasileiras. Dissertação de Mestrado. Brasília, DF, Brasil.

Desai, M. A., \& Dharmapala, D. (2006). Corporate tax avoidance and high-powered incentives. Journal of Financial Economics, 79(1), 145-179.

Dunbar, A., Higgins, D., Phillips, J., \& Plesko, G. (2010). What do measures of tax aggressiveness measure. In Proceedings of the National Tax Association Annual Conference on Taxation, 103(103),18-26.

Dyreng, S. D., Hanlon, M., \& Maydew, E. L. (2008). Long-run corporate tax avoidance. Accounting Review, 83(1), 61-82.

Edward, A., Schwab, C., \& Shevlin, T. (2015). Financial constraints and cash tax savings. The Accounting Review, 91(3), 859-881. 
Fabretti, L. C. (2012). Contabilidade Tributária (12a ed). São Paulo: Atlas.

Fernández-Rodríguez, E., \& Martínez-Arias, A. (2014). Determinants of the effective tax rate in the BRIC countries. Emerging Markets Finance and Trade, 50, 214-228.

Ferreira, G. M., \& de Souza, L. M. (2018). Planejamento Tributário: tendências de pesquisas nacionais e internacionais. Apresentado no XII Congresso ANPCONT, João Pessoa, PB, Brasil.

Giannini, S., \& Maggiulli, C. (2002). The effective tax rates in the EU Commission study on corporate taxation: Methodological aspects, main results and policy implications. CESifo Working Paper, 666(1) 1-29.

Gomes, A. P. M. (2016). Características da Governança Corporativa como Estímulo à Gestão Fiscal. Revista Contabilidade \& Finanças - USP, 27(71), 149-168.

Graham, J. R., \& Tucker, A. L. (2006). Tax shelters and corporate debt policy. Journal of Financial Economics, 81(3), 563-594.

Greco, M. A. (2008). Planejamento tributário. São Paulo: Dialética.

Hanlon, M. (2005). The persistence and pricing of earnings, accruals, and cash flows when firms have large book-tax differences. The accounting review, 80(1), 137-166.

Hanlon, M., \& Heitzman, S. (2010). A review of tax research. Journal of Accounting and Economics, 50(2-3), 127-178.

Instituto Brasileiro de Planejamento e Tributação (IBPT) (2018). Empresas listadas na bolsa de valores estão entre os maiores devedores de impostos no Brasil. Recuperado em: 15 de maio, 2019, de https://ibpt.com.br/noticia/2646/empresas-listadas-na-bolsa-de-valoresestao-entre-os-maiores-devedores-de-impostos-no-brasil

Instituto Brasileiro de Planejamento e Tributação (IBPT) (2019). Por que as empresas devem fazer uma análise do impacto tributário a cada ano? Recuperado em: 15 de maio, 2019, de $\quad$ https://ibpt.com.br/noticia/2771/Por-que-as-empresas-devem-fazer-uma-analise-doimpacto-tributario-a-cada-ano

Instituto de Pesquisa Econômica Aplicada (IPEA) (2015). As distorções de uma carga tributária regressiva. Recuperado em: 15 de maio, 2019, de http://www.ipea.gov.br/desafios/index.php?option=com content\&id=3233 
Katz, S. P., Khan, U., \& Schmidt, A. (2013). Tax avoidance and future profitability. Columbia Business School Research Paper, (13-10). Recuperado em 27, Janeiro, 2020, de https://papers.ssrn.com/sol3/papers.cfm?abstract_id=2227149

Kayo, E. K., Patrocínio, M. R., \& Martin, D. M. L. (2009). Intangibilidade e criação de valor em aquisições: o papel moderador do endividamento. Revista de AdministraçãoRAUSP, 44(1), 59-69.

Koenker, R. (2005). Quantile regression. Cambridge University Press, 349.

Kraft, A. (2014). What really affects German firms' effective tax rate?. International Journal of Financial Research, 5(3), 1-19.

Kume, H. (2019). Avaliação e reformulação da estrutura tarifária no Brasil. Pesquisa e Planejamento Econômico, 49(2), 7-31.

Lammersen, L. (2002). The measurement of effective tax rates: common themes in business management and economics. Discussion Paper, 02-46. Recuperado em: 15 de maio, 2019, de ftp://ftp.zew.de/pub/zew-docs/dp/dp0246.pdf

Lazăr, S. (2014). Determinants of the variability of corporate effective tax rates: Evidence from Romanian listed companies. Emerging Markets Finance and Trade, 50, 113-131.

Lima, F. B., \& Duarte, A. M. P. (2007). Planejamento Tributário: instrumento empresarial de estratégia competitiva. Qualitas Revista Eletrônica, 6(1).

Lopes, T. (2012). Custos Políticos Tributários: O impacto do tamanho na alíquota tributária efetiva. Tese de Doutorado. São Paulo, SP, Brasil.

Mamede, S. D. P. N., Nakamura, W. T., Nakamura, E. A. M. V., Jones, G. D. C., \& Jardim, J. R. D. P. S. (2017). Empresas brasileiras estatais e não estatais: uma análise das relações de endividamento. Revista Evidenciação Contábil \& Finanças, 5(2), 4-22.

Martinez, A. L., \& Salles, A. F. (2018). Agressividade tributária e cash holdings: Um estudo das companhias abertas brasileiras. Revista de Contabilidade da UFBA, 12(3), 4-23.

Martinez, A. L., Ribeiro, A. C., \& Funchal, B. (2015). The sarbanes oxley act and taxation: a study of the effects on the Tax Aggressiveness of Brazilian Firms. Apresentado no XV Congresso USP Controladoria e Contabilidade. São Paulo, SP, Brasil.

Martins, L. F. de C. (2014). O planejamento tributário como ferramenta de gestão nas empresas comerciais varejistas de Varginha/MG. Dissertação de Mestrado. Pedro Leopoldo, MG, Brasil. 
Medeiros, O. R., \& Daher, C. E. (2008). Testando teorias alternativas sobre a estrutura de capital nas empresas brasileiras. Revista de Administração Contemporânea, 12(1), 177199.

Megarani, N., Warno, W., \& Fauzi, M. (2019). The effect of tax planning, company value, and leverage on income smoothing practices in companies listed on Jakarta Islamic Index. Journal of Islamic Accounting and Finance Research, 1(1), 139-162.

Mills, L. F. (1998). Book-tax differences and Internal Revenue Service adjustments. Journal of Accounting research, 36(2), 343-356.

Modigliani, F., \& Miller, M. H. (1963). Corporate income taxes and the cost of capital: a correction. The American economic review, 53(1), 433-443.

Myers, S. (1984). The capital structure puzzle. The journal of Finance, 39(1), 575-592.

Parente, P. S. P. (2011). Os Comportamentos Empresariais e a Evasão Fiscal-Classificação das Empresas da Indústria dos Componentes para Calçado. Dissertação de Mestrado. Porto, PT, Portugal.

Paste, E. Jr. (2017). Eficiência das empresas e agressividade tributária: evidências do Brasil. Dissertação de Mestrado. Vitória, ES, Brasil.

Paula, D. G. (2018). O planejamento tributário como instrumento de competitividade empresarial. Revista de Finanças Públicas, Tributação e Desenvolvimento, 6(7), 16-32.

Perez, M. M., \& Martins, R. D. C. S. (2005). Decifrando a geração de valor ao acionista. Apresentado no Encontro Nacional da Associação Nacional dos Programas de Pós-Graduação em Administração. Brasília, DF, Brasil.

Pohlmann, M. (2005). Contribuição ao estudo da classificação interdisciplinar da pesquisa tributária e do impacto da tributação na estrutura de capital das empresas no Brasil. Tese de Doutorado. São Paulo, SP, Brasil.

Pohlmann, M. C., \& De Iudícibus, S. (2010). Relação entre a tributação do lucro e a estrutura de capital das grandes empresas no Brasil. Revista Contabilidade \& Finanças, 21(53), 1 25 .

Rajan, R. G., \& Zingales, L. (1995). What do we know about capital structure? Some evidence from international data. The Journal of Finance, 50(5), 1421-1460. 
Ramalhosa, M. M. C. (2015). Determinantes da Taxa Efetiva de Imposto: Análise Econométrica do Setor Automóvel em Portugal. Dissertação de Mestrado, Porto, PT, Portugal.

Rashid, H., Anderson, M. \& Warsame, H. (2019). Financial Security Issuance and Cash Savings through Tax Planning. Recuperado em: 31 de janeiro, 2020, de https://scholarspace.manoa.hawaii.edu/handle/10125/64923?mode=full

Rego, S. O., \& Wilson, R. (2012). Equity risk incentives and corporate tax aggressiveness. Journal of Accounting Research, 50(3), 775-810.

Rezende, A. J., Dalmácio, F. Z., \& Rathke, A. A. T. (2019). Avaliação do impacto dos incentivos fiscais sobre os retornos e as políticas de investimento e financiamento das empresas. Revista Universo Contábil, 14(4), 28-49.

Rezende, G. P.; Nakao, S. H. Gerenciamento de resultados e a relação com o lucro tributável das empresas brasileiras de capital aberto. Revista Universo Contábil,8(1), 6-21, 2012.

Sant'Ana, J. A. A. (2001). A relação entre endividamento e rentabilidade nas empresas brasileiras de 1996 a 2000. Contabilidade, Gestão e Governança, 4(2), 109-133.

Santana, S. L. L. (2014). Planejamento tributário e o valor da firma no mercado de capitais brasileiro. Dissertação de mestrado. São Paulo, SP, Brasil.

Santos, M. A. C., Cavalcante, P. R. N., \& Rodrigues, R. N. (2013). Tamanho da firma e outros determinantes da tributação efetiva sobre o lucro no Brasil. Advances in Scientific and Applied Accounting, 6(2), 179-210.

Shackelford, D. A., \& Shevlin, T. (2001). Empirical tax research in accounting. Journal of accounting and economics, 31(1), 321-387.

Shevlin, T. (1999) A Critique of Plesko's “An Evaluation of Alternative Measures of Corporate Tax Rates". University of Washington.

Silva, A. D. F., \& Valle, M. R. D. (2008). Análise da estrutura de endividamento: um estudo comparativo entre empresas brasileiras e americanas. Revista de Administração Contemporânea, 12(1), 201-229.

Silva, F. P., \& Maciel, D. C. M. (2014). Análise do Impacto da FIN 48, Do Fasb, No Montante de Tributos Apurado Sobre o Lucro das Empresas Brasileiras Pela Ótica da Teoria dos Custos Políticos. Apresentado no Congresso USP de Controladoria e Contabilidade. São Paulo, SP, Brasil. 
Silva, J. R. D. M., de Ávila, L. A. C., \& Malaquias, R. F. (2013). Tipos e intensidade de serviços prestados por escritórios de contabilidade: uma análise da prestação de serviços de planejamento tributário. Revista de Contabilidade do Mestrado em Ciências Contábeis da UERJ, 17(3), 60-77.

Stickney, C. P., \& McGee, V. E. (1982). Effective corporate tax rates the effect of size, capital intensity, leverage, and other factors. Journal of accounting and public policy, 1(2), 125152.

Tang, T. Y. H. (2005). The Market Perception of BTD: an empirical study in China's capital markets. The Accounting Review. 1-37. Recuperado em: 28 de janeiro, 2020, de https://papers.ssrn.com/sol3/papers.cfm?abstract id=927167

Terra, P. R. S. (2007). Estrutura de capital e fatores macroeconômicos na América Latina. Revista de Administração, 42(2), 192-204.

Vello, A. P. C., \& Martinez, A. L. (2014). Planejamento tributário eficiente: uma análise de sua relação com o risco de mercado. Revista Contemporânea de Contabilidade, 11(23), 117140.

Wilkie, P. J. (1992) Empirical evidence of implicit taxes in the corporate sector. The Journal of the American Taxation Association, 14, (1), 97.

Submetido em: 13.11.2020

Aceito em: $\quad 25.01 .2021$ 